\title{
Do policymakers use social media for policy design? A Twitter Analytics Approach
}

\author{
Ashish Kumar Rathore \\ Great Lakes Institute of Management, Chennai, India \\ ashish.r@greatlakes.edu.in
}

\section{Dayashankar Maurya}

International University of Japan

\section{Amit Kumar Srivastava}

T A Pai Management Institute, India

\section{Abstract}

Social media has been widely used for communicating information, awareness, and promote public policies by government agencies. However, limited attention has been paid to the use of social media in improving the design of public policies. This paper explores to what extent citizens' opinions and responses expressed on social media platforms contribute to policy design. The paper analyzes discussion about the 'Ayushman Bharat' scheme on Twitter through social media analytics techniques such as content analytics and then traces the change in policy design over two years. To validate findings from Twitter data, and assess the evolution in policy design, we conducted in-depth interviews with experts and extensive document analysis. The paper reveals that consistently similar issues were raised by experts in the past as well as by citizens in the current scheme. However, over time policy design has not changed significantly. Therefore, despite a strong social media presence, its optimum use to improve policy effectiveness is yet to be achieved. The paper contributes by exploring the role social media can play in the public policy process and policy design in developing countries' contexts and identifies gaps in existing social media strategies of public agencies.

Keywords: Social Media, Twitter Analytics, Public Policy, Policy Co-Design, Policy Responsiveness

\section{Introduction}

Policy design is considered to be the core of effective public policy (Peters, 2015; Howlett, 2019). In developing country context, poor policy designs have been common due to the high incidence of bargaining, corruption of clientelism, log rolling, electoral opportunism, and capacity constraints (Boubakri et al., 2008; Bali \& Ramesh, 2015). Limited policy monitoring and the use of data remain crucial constraints in improving policy design in developing countries (Khawaja, 2011; Holvoet \& Inberg, 2014). The emergence of Social Media (SM) platforms has made it easy and cost-efficient to capture citizens' reactions and opinions on a public policy or scheme (Eze et al., 2016; Miah et al., 2017; Morgan et al., 2018; Aswani et al., $2018 \mathrm{~b})$. In recent years, SM has emerged as a powerful tool to engage various stakeholders in the knowledge exchange process (Corcoran \& Duane, 2018; Morgan et al., 2018; Lim et al., 2019), and government agencies are also actively using SM for various purposes (Chun \& Luna-Reyes, 2012; Linders, 2012; Malsbender et al., 2014; Hacker et al., 2017; Eom et al., 2018; Hedestig et al., 2018). However, little is known about the use of Social Media Analytics (SMA) in policy co-design, which requires policy designers and citizens to come together to design solutions to problems critical to improving the effectiveness of policy design. 
This paper explores a social health insurance program called 'Ayushman Bharat' in India to investigate the extent to which public agencies use citizens' opinions and expectations to improve the design of this scheme. The paper uses SMA to obtain a generic and bigger picture of citizens' opinions to analyze scheme-related posts. The posts were collected from Twitter, a microblogging SM platform that contains various metadata information that can be collected cost-effectively (Aleti et al., 2016; Rathore et al., 2017; Aswani et al., 2018a; Grover et al., 2018).

India has experimented with several social health insurance schemes over the last six decades, but 'Ayushman Bharat' launched in 2018 has been the most ambitious public health insurance scheme. Given the experience of citizens with previous social health insurance schemes over the last two decades, citizens are expected to be well informed on the issues related to social health insurance programs. In this paper, we mapped the SM responses of citizens at the launch of 'Ayushman Bharat' in 2018 to identify the critical concerns related to its design. This was followed by tracing the evolution of program design from August 2018 to May 2020 using document analysis and in-depth interviews assessing the extent to which the program designers responded to concerns expressed by citizens.

The findings suggest that although agencies implementing the 'Ayushman Bharat' program has a significant presence on SM and tend to use SM to address grievances expressed by citizens and other stakeholders, their use of SM for co-design has been limited. The concerns expressed by citizens at the time of the program's launch have been consistently the same as those identified by experts based on their experience of similar social health insurance schemes in the past. Even though SM has been used by agencies, there have been only limited efforts to improve the program's design. Thus, program designers are yet to use online platforms to engage stakeholders in policy design, especially in developing countries. This paper seeks to fill the literature gap on the online engagement of stakeholders in the policy co-design using $\mathrm{SM}$ to design effective public policies.

The paper contributes to (a) the policy co-design process, which has received limited attention in the literature; and (b) the role of SM in the public policy process in the developing countries' context. Finally, the paper highlights the gaps in existing strategies of SM usage by public agencies in developing countries. The paper was been divided into seven sections. The first section introduces the need and scope of SM in designing healthcare schemes in developing countries such as India. The second section includes the existing literature on the policy design domain and that on Social Media Monitoring (SMM) (Bekkers et al., 2013). The third section introduces the research context of the paper. The fourth section explains the research methodology used in this paper. The fifth section demonstrates the results of the analysis. The sixth section discusses the implications of insights from the previous section. The last section contains the concluding remarks, followed by the limitations of current work and future directions.

\section{Theoretical Background}

Poor policy design is considered a critical reason for policy failure (Peters, 2015; Peters et al., 2018). Theoretical frameworks in policy design refer to policy design as a process of conscious and deliberate effort to define policy aims and select policy tools (such as taxes, regulations, etc.) and calibrate policy tools to achieve specific outcomes (Peters et al., 2018; Howlett, 2019). Evidence-based policy design needs policy actors to aggregate, communicate and manage knowledge resources on what policy tools work, in what conditions, and how they are being 
perceived by target groups (Peters et al., 2018; Howlett, 2019). Theoretical policy design frameworks suggest that even though the goal of policy design is to invoke the desired behavioral change in the target group, various barriers and impediments may prevent it. For example, compliance with a policy by citizens depends upon their perception of the legality, normative and moral appropriateness of the policy and the capability and resources citizens must use to be compliant (Wan et al., 2015; Howlett, 2019). Therefore, this uncertainty about the compliance of citizens with the intention of the designed policy is one of the critical challenges of policy design (Howlett, 2019). One of the ways to address this is actively engaging with target groups after the policy is launched to improve the design in case the target group's compliance is not forthcoming.

\subsection{Public Opinion and Communicative Action for Policy Co-design}

The theoretical frameworks in policy design give primacy to actors in policy subsystems such as experts, political actors, and bureaucrats as a policy is generally designed by bureaucrats, politicians, and consultants; therefore, the process is dominated by experts (Howlett et al., 2015; Howlett, 2019). However, recent trends suggest that citizens could also be fruitfully involved in the policy design process referred to as co-design. Co-design involves "enabling or empowering the people affected by a policy issue to actively contribute to developing a solution for it" (Blomkamp, 2018, pg. 732). Co-design is argued to improve idea generation, service delivery, project management, and longer-term outcomes (Steen et al., 2011). However, challenges remain regarding how to collect public opinion and involve citizens in the codesign process.

Collecting and using public opinion is not a straightforward process as public opinion is usually strong and diverse on critical, long-term issues (Zaller, 1992) but limited in the case of complex and arcane issues (Arnold, 1990). Second, even though public opinion is collected, how it is used depends on the relationship between the user of the information and the provider of the information, as the Habermas 'theory of communicative action' suggests ((Habermas, 1984; Habermas, 2015). This theory suggests three distinct ways in which the information collected may be used. First, in a rational or instrumental approach, the user aims at realizing pre-given goals using the information provided about the environment by citizens and the nomological knowledge about effective intervention. In the second approach, known as the political-strategic approach, the user of the information considers the goals and power resources of the provider of the information and alternative actions available to the provider. In the third approach, known as the communicative approach, the user of the information seeks to reach a common understanding with the providers of the information, especially about the interpretation of the problem. As the Habermas theory of communicative action suggests, even though citizens are involved in the co-design process, the outcome of the process will depend upon how the provided information is used. For a policy co-design process to happen, information needs to be used in the communicative approach rather than in the rational and strategic approaches.

\subsection{Citizens' Engagement through SM for Policy Co-design}

In recent years, SM has provided a fast and cost-effective opportunity to obtain public opinion on policy issues and are considered to have the potential to reform public administration (Linders, 2012; Medaglia \& Zheng, 2017). Governments are using SM to improve transparency, the dissemination of policy information (Bertot et al., 2010; Linders, 2012), citizen engagement (Criado et al., 2013; Gintova, 2019), and the co-production of services (Loukis et al., 2017; 
Hedestig et al., 2018). However, critics argue that SM is used mainly for self-promotion and political marketing rather than improving transparency, participation, and service delivery (Picazo-Vela et al., 2016; Medaglia \& Zheng, 2017). Given the extensive use of SM by public agencies, $\mathrm{SM}$ is considered to have the extensive potential for improving policy design. However, there has been minimal discussion on using SM in the policy design process (Loukis et al., 2017; Hedestig et al., 2018). Existing policy co-design approaches use crowdsourcing and digital participatory platforms to engage citizens (Taeihagh, 2017; Falco \& Kleinhans, 2019), but there has been little research on the use of SM for the same purpose, even though SM is used much more extensively, even in developing country contexts.

One of the approaches to using SM in co-design is SMM. SMM has been defined as the continuous, systematic observation and analysis of SM networks and social communities (Fensel et al., 2012; Bekkers et al., 2013). Using SMM, the government can passively monitor SM communities related to a specific topic or policy (Loukis \& Charalabidis, 2015; Loukis et al., 2017). However, to access knowledge from SM content, SMM is not enough. The limitation of SMM can be addressed by SMA as it is a more appropriate approach to understand the influence of different stakeholders (Rathore et al., 2017; Aswani et al., 2018a; Grover et al., 2019b). Many businesses have been using SMA to collect knowledge, ideas, and opinions about their products and services from users to improve the design of their products and services (Zhang \& Vos, 2014; Rathore \& Illavarasan, 2020). However, research on the use of SMA for coproduction by public agencies is scarce (Loukis et al., 2017; Hedestig et al., 2018). Through the co-design process, governments can gain much by collecting citizens' inputs through SM platforms to improve the design of public services in an evidence-based manner (Androutsopoulou \& Charalabidis, 2018; Alizedah et al., 2019). Applying the theory of communicative action (Habermas, 1984), SMA can also take one of the following three approaches based on how the information is used. First, in a rational approach, SMA can be used to determine the situation of the policy and intervene by using normative knowledge. Second, in a political-strategic approach, SMA can be used to assess what is being said about the policy, and that information can be used for reputation management. Third, in the communicative approach, SMA can be used for co-design purposes whereby government agencies and citizens come together to form a shared definition of the situations, problems, and policies that can be used to improve existing policies or design new policies based on the principle of collective intelligence (Surowiecki, 2004).

\subsection{Communicative Approach of SMA for Policy Co-design}

For co-design, the use of SMA requires adopting a communicative approach (Linders, 2012; Bekkers et al., 2013). In this approach, first, government agencies gather information about citizens' perceptions, grievances, and demands and obtain feedback about the policies that are being developed or implemented. This is followed by responding to this information by engaging and interacting to generate new ideas and policy improvements (Linders, 2012). Although co-design using SMA could be very cost-efficient and quick, it has its own set of challenges. Co-design requires extensive coordination to manage and balance diverse objectives and interests in a time-bound manner (Blomkamp, 2018). Apart from usual difficulties in the use of SMA by governments, such as irrelevant noise and chatter, the reliability and quality of information, information overload, political risks, and privacy violations (Beer \& Burrows, 2007; Sutton, 2009), there are additional challenges for using SMA in co-design. The first challenge is obtaining a representative from every segment of the population; otherwise, the data could be considered to be biased (Euripidis et al., 2017). 
Second, population groups that do not have access to the internet are left out, leading to participation inequalities (Brabham, 2012). The third challenge is the capability of government agencies to manage SM and the co-design process (Blomkamp, 2018; Netshakhuma, 2019). Public opinion research suggests that public opinion is expected to be high if the information is available to all (Downs, 1957; Becker, 1983; Williamson, 1993), but most often groups placing pressure determine the issues (Grindle \& Thomas, 1991; Berry \& Wilcox, 2018), which may be different from public opinion (Wright, 1996; Domhoff, 1998; Medaglia \& Zheng, 2017).

As the use of SM among public agencies, departments, and programs to disseminate information has increased considerably in developing countries (Warf, 2016; Verma et al., 2017), there is little evidence on whether citizens' feedback on SM platforms for various programs and policies is taken into account by public agencies. Public agencies in developing countries such as India engage in SMA, as seen from the number of incidences where public agencies have addressed the grievances raised by citizens on SM platforms (Agarwal et al., 2017; Goyal et al., 2020). However, to what extent SMA is used to improve the design of public services through SM activism remains unknown (Poell \& Rajagopalan, 2015). Using a case study approach, this paper explores whether the input provided on SM by citizens about public service at the launch of the policy is considered and addressed by the policy designers over a period. Thus, this paper explores the empirical evidence on policy design using SM.

\section{Research Context}

In a democratic setting such as India, with a high frequency of elections and a large number of political parties, making elected members accountable for policies is difficult, especially for low salience issues (Arnold, 1990; Jones, 1994; Lindaman \& Haider-Markel, 2002). However, public opinion has informally determined various populist policies in India, as observed by other studies (Kumar \& Sharma, 2017; Chatterjee, 2019b). We explored the role of public opinion expressed on SM platforms for policy co-design in the case of a large-scale Public Health Insurance (PHI) scheme, 'Ayushman Bharat', one of several programs that were launched by the government in the last two decades.

In 2014-2015, federal and provincial governments spent approximately INR 25000 million (330.55 million USD) on approximately 15 PHI schemes (IRDA, 2016). PHI schemes have provided health insurance to 214.3 million more persons over the past decade, contributing to approximately $74 \%$ of the total health insurance coverage in India (IRDA Annual Report, 2016). PHI targets low-income households and is entirely financed by the public sector while service delivery is managed by contracted for-profit insurance companies and private hospitals.

Over the years, experts have highlighted several critical issues in the design of PHI schemes. First, PHI schemes were criticized for not including ambulatory care, which contributed to $65 \%$ of the out-of-pocket healthcare expenditures (National Sample Survey Office, 2015). Second, fraudulent behavior was observed among all stakeholders primarily due to the fixed cost payment system and limited quality monitoring (Maurya, 2018; Maurya \& Ramesh, 2019). The packages in the schemes and standard of care were poorly defined, allowing hospitals to manipulate these items (La Forgia \& Nagpal, 2012; Maurya, 2018). Third, beneficiaries faced challenges in enrolling either because the poverty registers were faulty, their names were not printed correctly, or they never received an identification card to access services. The beneficiaries also lacked information about what kind of services are covered by insurance. 
Fourth, the coverage of most of the PHI schemes was considered shallow, ranging from 30,000 to 100,000 INR per family per year (Asher et al., 2015). Finally, although PHI schemes have experienced increased utilization among enrolled individuals (Prinja et al., 2017), no reduction in healthcare expenditures among beneficiaries was observed (Mitchell et al., 2011; Gupta et al., 2017; Prinja et al., 2017).

On September 23, 2018, the Government of India (GOI) launched the 'Ayushman Bharat' scheme, also referred to as 'Pradhan Mantri Jan Arogya Yojana' (PMJAY). The scheme had a similar design to the previous PHI schemes but with some modifications. Similar to previous PHI schemes, in 'Ayushman Bharat', provincial governments also contracted with private and public hospitals based on defined packages of services. However, in 'Ayushman Bharat', the government aimed to enroll 500 million families in the program, which was much higher than the number in previous PHI schemes. Each family is supposed to obtain healthcare coverage of 500,000 INR per year that can be used at any of the contracted public or private hospitals (Business Line, 2018). The healthcare package included the costs of hospitalization, investigations, food, drugs, and some prehospitalization care. By June 21, 2020, 125 million families were enrolled in the scheme, more than 22,000 hospitals were contracted, and more than 10.7 million hospitalizations were covered by the scheme.

The 'Ayushman Bharat' program is managed by the National Health Authority (NHA), which joined Twitter in May 2018. The account is followed by more than 52 thousand followers. In addition, each district where the program is implemented has its own Twitter handle. The NHA regularly responds to the concerns and grievances related to the services delivered raised on Twitter by beneficiaries. Apart from beneficiaries, other stakeholders such as experts, insurance companies, and hospitals tend to use Twitter to voice their concerns, suggesting that some form of coproduction and coordination is taking place using SM. However, to what extent the feedback by citizens on the design of the program is used to improve the design is not known. Therefore, the research questions that this paper seeks to address are as follows:

- What were the key issues, concerns, and sentiments expressed by the citizens about the 'Ayushman Bharat' scheme on SM platforms?

- $\quad$ Does SMA by policy designers improve policy design and to what extent?

\section{Methodology}

Following the research tradition of the multimethod approach (Hambrick \& Abrahamson, 1995; Cyr et al., 2009), we adopted a two-stage methodology (Lin, 2014; Akrout \& Diallo, 2017). The first stage is SMA which includes data extraction and analysis from Twitter, and the second stage is semistructured interviews of health experts associated with the 'Ayushman Bharat' scheme. An interview-based qualitative study can validate the findings of SMA. SMA is a cost-effective approach that provides real-time insights to the government to gauge public needs and sentiments (He \& Yan, 2014). It helps in analyzing citizens' emotions captured through their posts (Melville et al., 2009; Huh et al., 2013; Tuarob et al., 2014). It also helps the government in policy design and redesign (Lau et al., 2014). However, the existing SMA methods often adopt context-free sentiment analysis. Therefore, methods for the fine-grained extraction of public intelligence from User-Generated Content (UGC) are required to aid policy design processes. The data on Twitter is predominantly textual content, the most likely nature of content with SM posts, reflecting citizens' emotions. As of 2020, there are 275 million Twitter users (Statista, 2020), and its usage has been increasing in both business and non- 
business domains. Common citizens have also made Twitter part of their daily routines to share their experiences. Features such as the strict character limit of up to 280 characters, called tweets, make Twitter data more concise and expressive than the data of other SM platforms such as Facebook (Pak \& Paroubek, 2010; Rathore et al., 2017). Short-form features categorize them in the special case of the social-emotional context to evaluate collective sentiments (Hodeghatta \& Sahney, 2016). Twitter data represent real events in terms of personal opinions, public knowledge, and collective sentiment (Rathore et al., 2016; Zhang et al., 2016; Grover et al., 2019b). Users do not need to have reciprocal relationships to share and access other users' content. This phenomenon is referred to as asymmetric connections in the literature (Wakefield \& Wakefield, 2016). It seems more appropriate to think of tweets as public announcements rather than private conversations.

This paper analyzes tweets on the 'Ayushman Bharat' scheme to analyze public discussion and sentiment that can facilitate reflection on policy design. Determining topics with the associated polarity, negative and positive, presents the relationship between the sentiment of comments and the ratings of different aspects of the scheme (Cao et al., 2013). In the following paragraphs, both stages of the adopted approach are presented. Stage 1 involves extracting and analyzing Twitter data (Figure 1), implemented through an R application using different scripts. Stage 2 includes semi-structured interviews with experts in the domain of the research context, which are then subjected to document and secondary data analysis.

\subsection{Stage 1: Empirical Twitter Analytics}

\subsubsection{Data Preprocessing}

First, we selected the event, i.e., the launch of the 'Ayushman Bharat' scheme in India. The choice of this event is driven by the fact that it is the world's largest public health insurance scheme, and it has drawn significant attention from all key stakeholders, including citizens. Therefore, 'Ayushman Bharat', as the event, was able to generate enough user-generated content for the analysis. The next part includes different steps, including keyword selection, tweet extraction, and tweet preparation. We used Twitter, a microblogging platform, as the data source. To determine the most appropriate keywords related to the event and avoid nonrelated events having similar kinds of discussion, we selected keywords from Twitter only. This approach not only provides valid keywords, but it also provides the posting rate for the content, which is useful for predicting the data volume for a specific time interval. Using selected keywords, tweets are retrieved using 'R,' an open-source tool. To perform the search, an $\mathrm{R}$ script was created to download the tweets weekly. The posts/comments were collected weekly through a Twitter search API (Application Programming Interface). To create our dataset, we used "\#AyushmanBharat" as the keyword, which resulted in a total of 46754 tweets collected during July 2018-July 2019. To clean the data, a tweet corpus is created using another package, "tm". This tweet corpus is used for all the analyses. Twitter data contain a variety of languages, unstructured abbreviations and grammar, and unofficial formats (Rathore et al., 2017; Grover et al. 2018). 


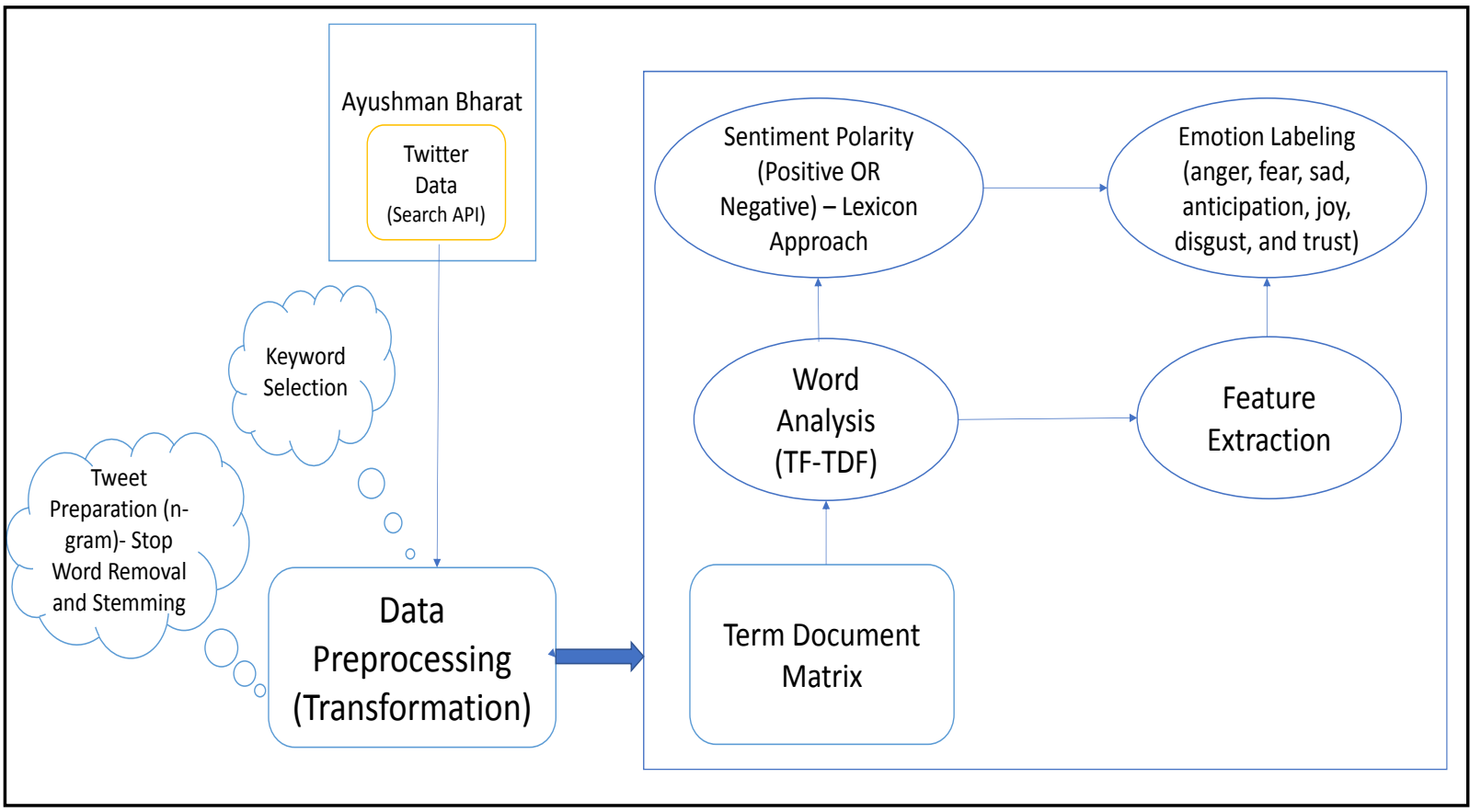

Figure 1. Data preprocessing and data analysis stages

Thus, to place the data in a meaningful format by removing unusual characters, datasets are formed through an automated text mining $\mathrm{R}$ script and along with the use of syntactic/semantic libraries (natural language packages) through the following techniques: removing stop words, tokenization, stemming and identifying n-grams.

\subsubsection{Data Analysis}

This paper adopts a content analysis approach to analyze tweets (Chae, 2015; Grover et al., 2019a; Rathore et al., 2020). Content analytics includes two parts - text analytics (identifying themes) and sentiment analysis (analyzing emotions) (Chau \& Xu, 2012; Feldman, 2013; Yoon et al., 2013; Chae, 2015). First, various themes have been recognized using different tools ( $R$ $\operatorname{Codes}^{1}$ ) to obtain a clear picture of citizens' preferences and expectations. The findings from ideation are prerequisites for sentiment analysis for the intelligent gathering of collective emotions associated with each of the aspects of the scheme. While text analytics (e.g., word frequency, clustering, word association, etc.) emphasizes the facts in the form of various themes, sentiment analysis provides more subjective information (e.g., emotions) in those themes. It classifies all different themes into broader emotions. Sentiment word clustering groups the major words into emotional clusters, which are further linked with various themes identified in text analytics.

\subsubsection{Text Analytics}

As a vast amount of data is generated from public reactions related to the scheme, many dynamic topics are associated with UGC (Aggarwal \& Subbian, 2012; Rathore et al., 2017). A traditional text analytics approach has been followed to address Twitter data (Figure 2). Topic modeling is one of the most effective approaches to identify different themes from UGC. In this paper, the Latent Dirichlet Allocation (LDA) approach was used for topic modeling (Yang \& Zhang, 2018). LDA “considers each document as a multinomial distribution over topics and

\footnotetext{
${ }^{1}$ https://drive.google.com/file/d/1TmuPGVMO03rkPQJ9SzMZmm7ATqLIX9wm/view?usp=sharing
} 
regards each to pic as a multinomial distribution over words" (Ren et al., 2016, pg. 4). The LDA approach does not need dissimilar streams to allocate vocabulary. It can be used to match words from different streams.

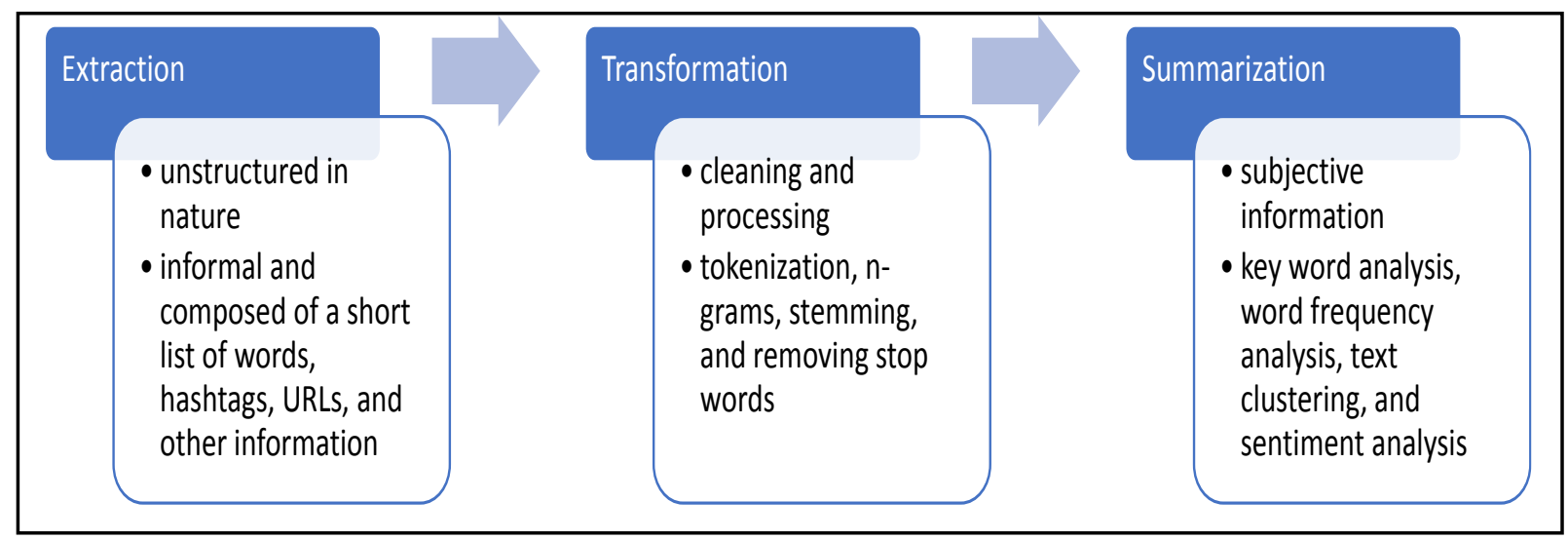

Figure 2. Text analytics process (Source: Chau $\mathcal{E}$ Xu, 2012; Feldman, 2013; Pang $\mathcal{E}$ Lee, 2009)

In the first stage, scheme-related topics are discovered using a data matrix approach, including various techniques such as word clouds, frequency distributions, clustering, and word association. The basic parameters for all mentioned techniques are word counts and the relationships among words. These are visualized using different two-dimensional graphs. Such a word frequency-based approach creates a very noisy corpus. Word frequency analysis includes word clouds based on the frequency distribution of each word. The frequency range varies from one to $1000+$ among the words in a single dataset. After analyzing the frequency distribution, we found that few words with high frequency such as 'ayushman', 'bharat', and 'scheme' are very common. In fact, these words do not contribute significantly to the body of the context. Additionally, more computational power is required to apply multiple approaches to a full corpus of words. Thus, we adopted a more robust approach, TF-IDF (Term FrequencyInverse Document Frequency) (Qaiser \& Ali, 2018; Curiskis et al., 2020), to obtain more significant words rather than frequent words. Comparing the output from the word frequency distribution and TF-IDF techniques showed that words with frequencies less than 100 are also at the bottom of the TF-IDF weight list. Therefore, a filter, i.e., for words with frequencies less than 100, has been applied, and these words are not considered in any further analysis in the paper. This also provides better visualization and analysis of word clouds.

This paper applies the combination of word clustering, and temporal segmentation helps to determine the different topics related to the scheme. Temporal segmentation differentiates various contextual aspects based on topical patterns (Cataldi et al., 2010). In this paper, topics are segmented using the relationship and connectivity among words. All these relationships and connectivity are based on the various edges and nodes, which lead to a structural form. This structure is used to conclude the occurrence-based topics. In addition, to recognize aspects based on different topics, latent aspect rating analysis (LARA) (Wang et al., 2010) was conducted, revealing the latent aspect ratings and aspect weights in every individual review. The integration of latent ratings and aspect weights strengthens the associated topic preferred by users. To illustrate it, a word network graph is created showing the various scheme aspects and interconnections among all. NodeXL, a commercial software program, has been used to perform thematic analysis, i.e., form a word clustering network. NodeXL is a widely used tool for social network analysis that does not need a programming language (Hansen et al., 2010; 
Ahmed \& Lugovic, 2019). Going beyond the identified topics, it is essential to understand the sentiment weight experience for different topics.

\subsubsection{Sentiment Analysis}

While retrieving topics and patterns in trends, there are approaches to recognize the polarity and emotions of different sentiments (Liu et al., 2008, Rathore et al., 2016). They include machine learning and the computational detection of the attitudes and opinions of users. These attitudes and opinions are related to the subjective knowledge about the scheme or different individual aspects of the healthcare initiative. To recognize more specific aspects, the relationships and correlations between words are very important compared to just distinguishing between positive and negative opinions based on polarity and emotions. These emotions reflect the relevant citizens' states of preferences. Thus, it is necessary to address the different aspects of the scheme in terms of hedonic aspects with the desired impacts. Sentiment analysis identifies the appropriate sensory aspects related to the policy design of the scheme with expressive details. Sentiment analysis is concerned with identifying new attributes of the utility of an emotional expression in policy design and implementation strategies. It also provides a cross-document opinionated summary of specific policy aspects that determine the degree of relevance and the degree of sentiment.

In this paper, the polarity determination of a textual corpus tends toward positive, negative, or neutral, offering a variety of benefits such as the prediction of emotional information in a citizen's choices (Cao et al., 2013). Tweets are categorized as having positive or negative polarity with a range of various emotion classifications. The contextual evaluation includes typical assessments, such as feeling, for different scheme aspects. Assuming users' posts are a function of the sentiments of their aspects, emotions are classified using sentence selection methods (King et al., 2013). This method is used to recognize the relevant words within each emotion ( $\mathrm{Ku}$ et al., 2006). This approach evaluates tweets based on the degree of sentiment polarity (e.g., positive and negative sentiments) on a scale of mapping numbers (e.g., -2 to +2 ). It provides a comparative assessment of the emotions useful for detecting the emotional variance of each citizen's statements. A large difference in sentiments would highlight the collective emotions in almost all aspects of the scheme. Second, a combination of n-gram and lexicon-based approaches is used to improve the accuracy of emotion and polarity classification, including different aspects such as parts-of-speech and negation terms (Barbosa \& Feng, 2010).

Based on a predefined set of sentiment classes, it is difficult to measure or evaluate aspects within the UGC for classifying its sentiment class in the context of the entity. Aspects are in forms of words that relate to any specific lexicon. For instance, it categorizes words into such defined emotions, such as joy, sadness, anger, disgust, fear, and anticipation, using frequency as sentiment values for each category (Fredrickson \& Losada, 2005). Mapping words in each tweet from a sentiment lexicon is used to evaluate the average emotion and polarity. This sentiment lexicon contains a directory of words that are associated with all classified emotions. In this research, symbolic aspects, based on hashtags, have been used for emotion classification decisions. It offers significant sentiment insights more accurately at predicting new scheme aspects. 


\subsection{Stage 2 - Semi-structured Interviews}

After Twitter analytics, qualitative data were gathered via a two-stage random cluster probability sample (Burger \& Silima, 2006; Henry et al., 2015). Interviews were conducted with health policy experts. For the first stage of the sample, one of the experts was selected via simple random sampling. That expert became the starting point for the interviews. Interviewers were instructed to seek eligible respondents at each starting point. Once an eligible respondent had been located, interviewers used a snowball approach to locate subsequent respondents. A total of 17 interviews, each running for 30-60 minutes, taking a total of approximately 12 hours were conducted. The in-depth interview guidelines were prepared based on the theory of policy design (Howlett et al., 2015), the design of social health insurance programs (Mathuer \& Carrin, 2011), and how different design elements have evolved over time. The data from the interviews were analyzed using thematic and contextual analysis (Meyer \& Goes, 1988; Nowell et al., 2017). The analysis focused on the nine design elements related to social health insurance programs. For each design element, using contextual analysis, we mapped the factors that drove the adoption of the particular design element and changes over time. The contextual analysis addresses contextual conditions policy actors, policy ideas, and existing institutional arrangements. We also extended the fourcriteria framework (Gibbert et al., 2008) to our research to ensure the validity and reliability of the qualitative research.

\section{Results and Findings}

\subsection{Text Analysis}

Text analysis, as demonstrated through a word cloud (Figure 2), results in the major words in the discussion on the 'Ayushman Bharat' scheme - "Haryana", "hospital", "claim" "first", "health", "girl", "welcome", "nitiaayog", "primari", "half", "million", "effort", "treatment", "pillar", "healthforall", "swasthbharat", "financialexpress", "vision", "aim", "beneficari", "two", "million", "care", "reform", "path", etc. (Figure 3). From these words, we can obtain small clues regarding citizens' reactions to the scheme's implementation and expectations. To discover topics, a clustering Figure 2). The approach highlights a few topics such as the first case of beneficiaries, the claim for childbirth in 'Haryana' (one of the states of the Republic of India), the aim to protect and provide schemes that serve as financial pillars for a million people, comprehensive primary care, path-breaking efforts, good employment opportunities, the 'public health cadre' as a new service sector for quality patient-centered primary healthcare services, a vision for their future in remote rural India, exempted reinsurance services (coverage up to ₹5 lakh per family per year to people over 10), reforming healthcare, and call centers for Prime Minister Jan Arogya Yojna. (Figure 3). There are few key challenges discussed in Twitter conversations - efficient coordination between the central and state government and insurance through other schemes such as maternal and child survival programs. Therefore, the clusters help in identifying the discussion related to various aspects of 'Ayushman Bharat' based on word occurrence. 


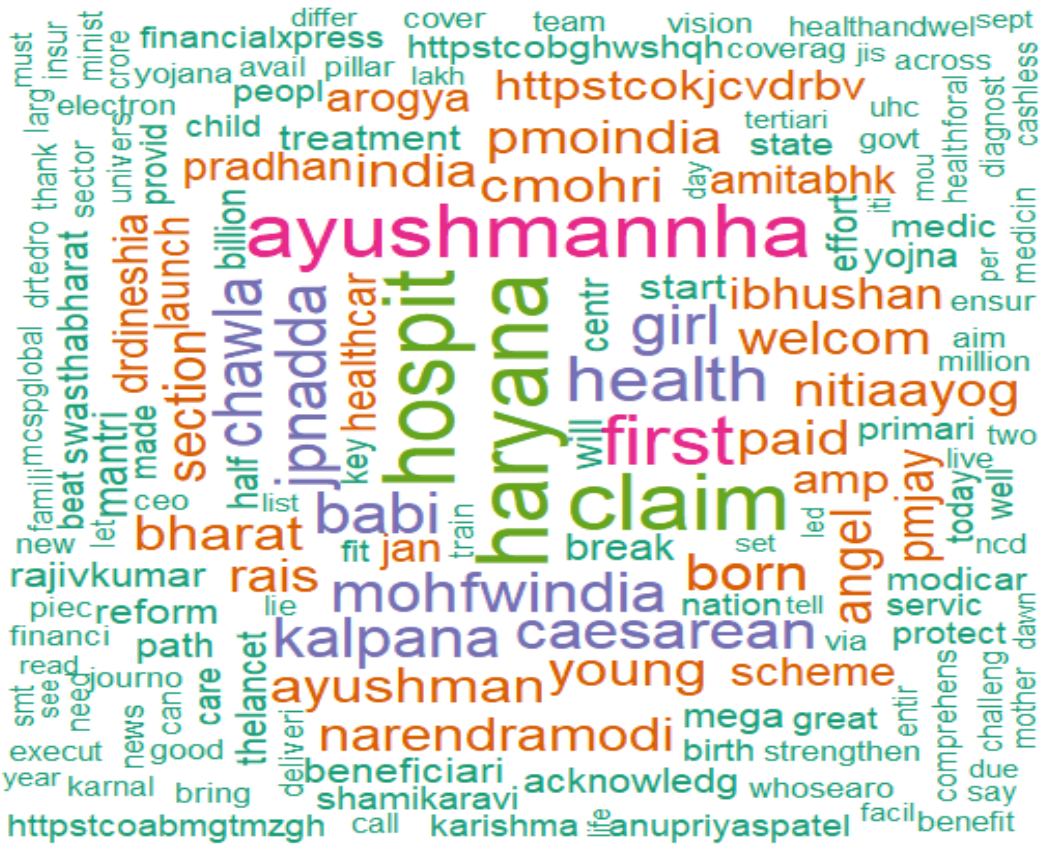

Figure 3. Word cloud for 'ayushman bharat'-related discussion

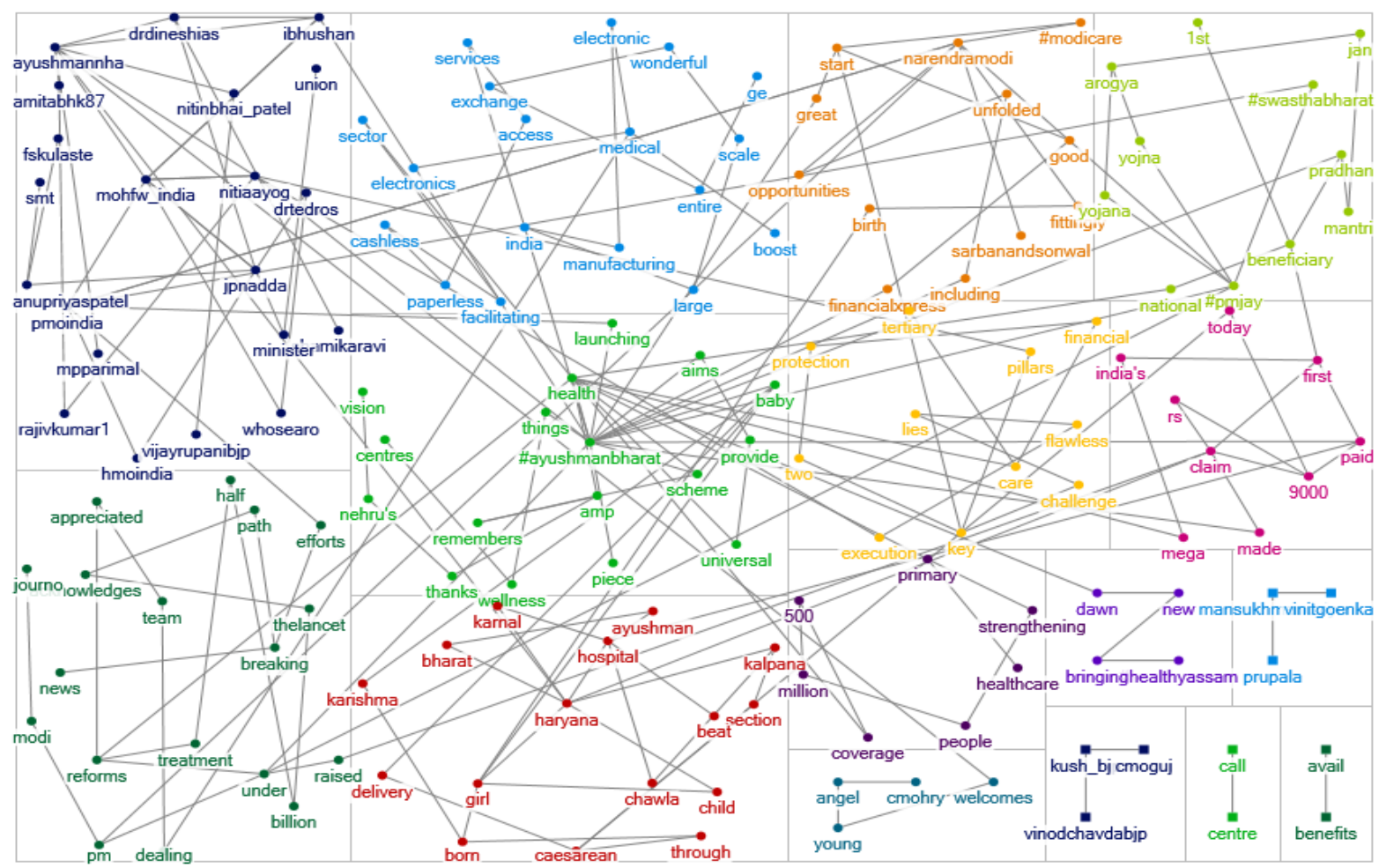

Figure 4. Thematic analysis

To use these topics, a word network clustering approach was used to highlight the themes associated with 'Ayushman Bharat' (Figure 4). There are a few clusters connected to each other. For instance, the first cluster has the center word 'ayushmannha' with single connected words such as 'mohfw_india', 'pmoindia', 'nitiaayog', and 'union minister' and various individual stakeholders who are associated with the healthcare sector such as the Minister of Health and Family Welfare, the Government of India, industry leaders such as the President of Reliance 
Industries Limited (RIL), top academic medical journals such as 'The Lancet' and medical professionals. Thus, stakeholders from diverse backgrounds are involved in covering multidimensional perspectives. Overall, the findings highlight various themes such as the financial benefits to people, treatments, claim amounts, different stakeholders, reform efforts to restructure healthcare, execution, and fraud detection mechanisms (e.g., digitization). There is also one dimension of the treatment theme that includes critical diseases, modern facilities through globalization, and robust processes.

\subsection{Sentiment Analysis}

There are more positive scores (approximately 65\%) associated with multiple topics. Trust has the highest score, suggesting that citizens are expecting more benefits from the scheme (Figure 5). Along with anticipation, joy emotion has the second-highest score, showing citizens' faith in the government. Thus, this shows that citizens have considerable expectations and, therefore, are looking forward to more responsiveness from the government. Fear and surprise also have noticeable scores that need to be addressed by policymakers. The surprise score indicates the presence of unexpected benefits such as health insurance coverage of up to Rs. 500,000 per family per year. However, there are few cases in which people did not obtain benefits because of a lack of awareness. Due to this, there is sadness due to the lack of awareness mechanism from the government.

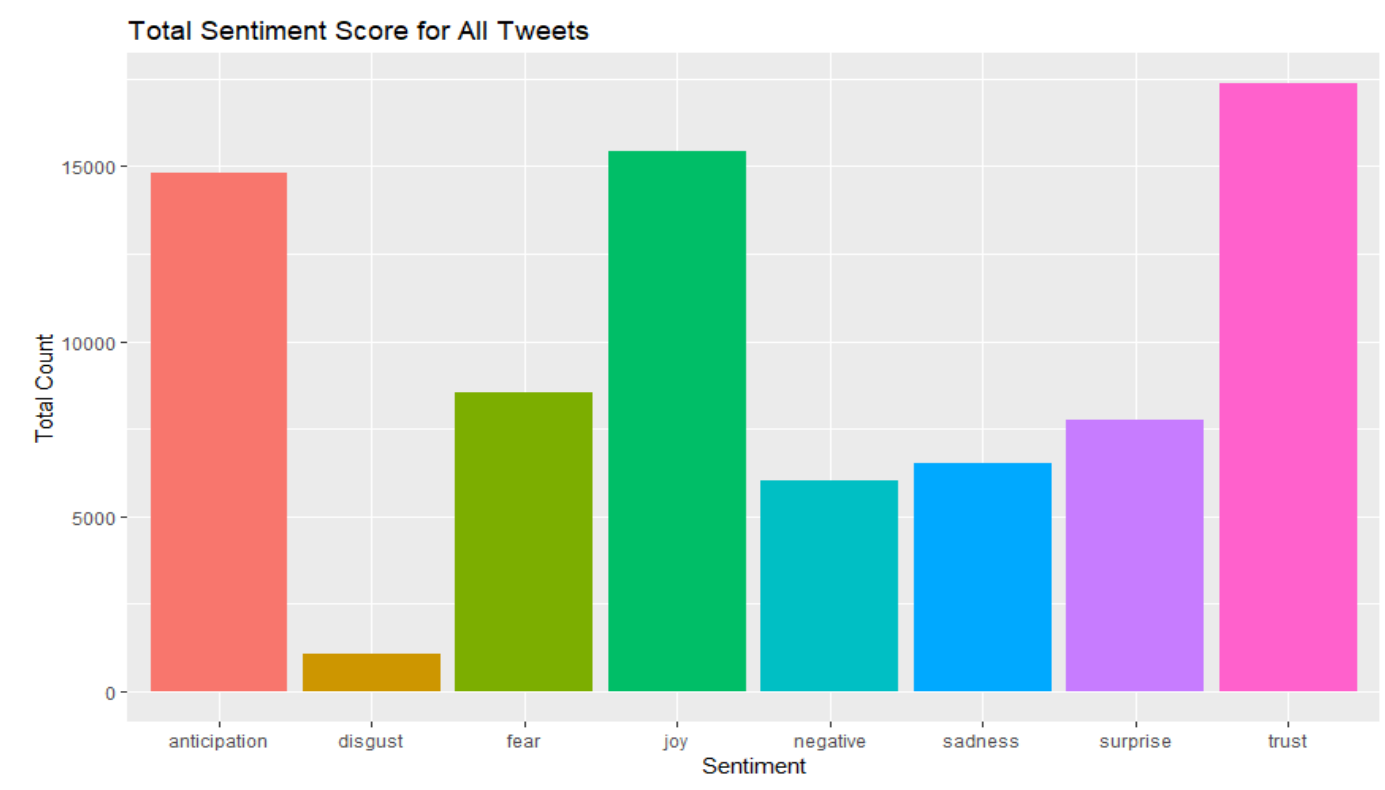

Figure 5. Emotion classification with frequency

As mentioned above, we further categorized all the results into major classes reflecting the positive and negative perspectives of the scheme from the citizens' point of view. The positive results show that the scheme is considered to be a bold and flawless effort to reform the healthcare sector in India (Figure 6). For instance, female childbirth is the first beneficial case under this scheme in the state of Haryana, supporting the role the scheme can play in addressing critical social issues such as the gender ratio. The response of the citizens indicates that the scheme strengthens the vision of developing a real partnership with the patients/beneficiaries. Most of the citizens consider the scheme robust and perceive it as a landmark of having modern facilities and expert service, which was out of reach for the majority of the citizens. Similarly, citizens are seeking the scheme's rapid acceptance and high 
reach to make it much more impactful. In the initial phase of its implementation, the scheme was perceived as having a high potential to have an impact on the healthcare sector.

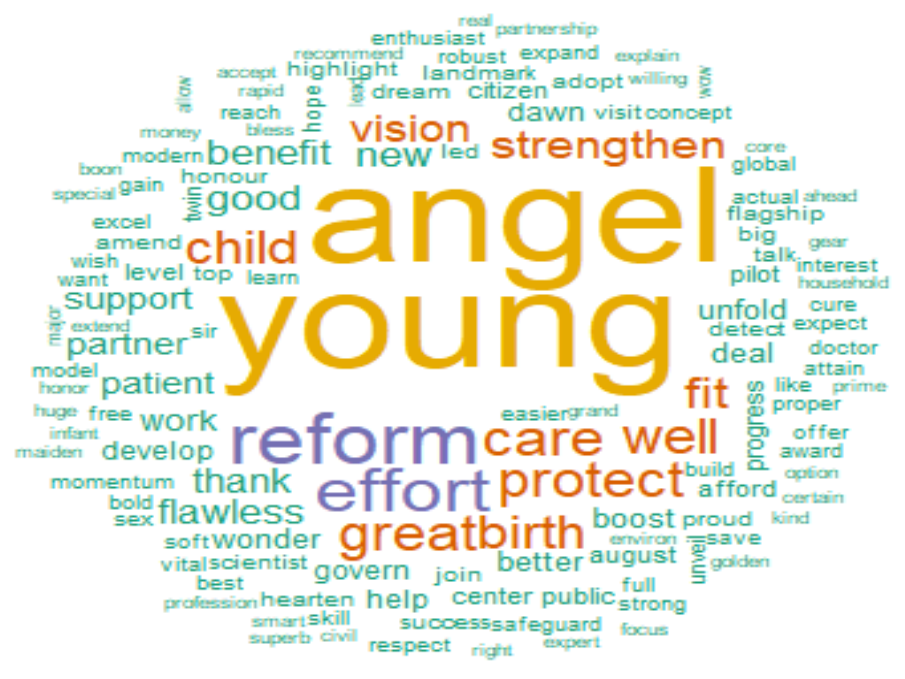

Figure 6. Word cloud for positive words

However, concerns were also expressed, which could be considered the negative side of the scheme (Figure 7). The major concern is the current information about the scheme and its accessibility. The scheme covers approximately half a billion people, which itself is a record number with treatment coverage. Therefore, first, a framework for the implementation of the scheme is required. Second, public systems need a safe and secure information infrastructure for the digitalization of all processes, i.e., cashless, paperless, etc. In summary, the scheme has significant benefits for approximately half a billion people but building the infrastructure to implement it is also a major challenge for the government.

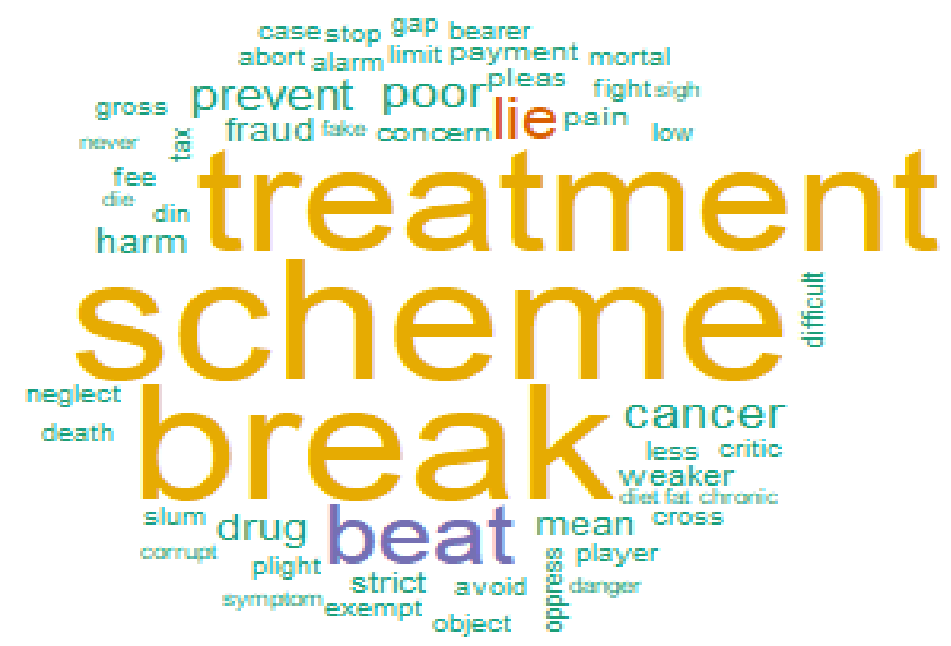

Figure 7. Word cloud for negative words

Another major concern is related to the transparency of the different processes. A lack of information about the type of diseases (e.g., cancer) covered under the scheme may restrict access to care. Another concern regards the charges for drugs and drug corruption. Another concern that was raised regards the coverage and financing of the scheme - which covers only 
the poor and not all taxpayers. The scheme primarily covers low-income families and is funded through general taxes. Low-income families do not contribute to direct taxes but are the primary beneficiaries of the program. Concerns were also expressed about additional expenses that would not be covered in the scheme. Thus, although respondents appreciated the scheme, they also had some concerns related to its design and implementation. Therefore, there is both considerable enthusiasm for the scheme and many concerns.

\section{Discussion}

Based on the results, the discussion is structured into four subsections. First, we assess the extent to which issues raised at the launch of the 'Ayushman Bharat' scheme have been addressed by the policy designers/program administrators in successive years. This is achieved using secondary data and expert interviews. Second, based on our case study, we discuss the usefulness of SM data in co-design. Finally, we discuss the value of SM in policy co-design during policy formulation in the country context of India.

\subsection{Policy Co-design: Matching Public Opinion with Evolution in Program Design}

The results presented above identify positive and negative sentiments reflecting the appreciations and concerns regarding the scheme at the time of its launch. In this section, we track the progress on the issues identified by experts over the years using primary and secondary data. We assess the extent to which program designers have addressed the concerns expressed by citizens at the time of launch of the scheme (refer to Table 1 and Table 2).

Positive sentiments: The positive sentiments about the scheme were primarily related to the scale and scope of the scheme. For all the positive topics, the data also include multiple positive words such as 'thank', 'honor', 'proud', 'golden', 'success', 'wow', 'huge', 'bless', 'good', 'bold', etc. (Table 1). The past schemes in India covered limited population groups, and the depth of the coverage was also minimal, as stated by various analysts (Asher et al., 2015; Prinja et al., 2017). Compared to other past schemes such as RSBY, the 'Ayushman Bharat' scheme is considered to be very ambitious as it covers approximately ten times the existing coverage of various schemes, and the depth of the coverage is increased by approximately 15 times. This is evident with Twitter users referring to the scheme as 'path-breaking' and 'visionary'.

Apart from the general public or beneficiaries, the scheme also received enthusiastic responses from private sector companies and hospitals as the scheme was launched in partnership with them. The scheme also received great support from various international development agencies, public health experts, and academic journals as they genuinely feel that the scheme can transform the Indian healthcare sector and address the vicious cycle of poverty and poor health. The former Director-General of the WHO, Bruntland (2018), noted in an article in "The Lancet' that "The reforms are to be welcomed because for decades India has underinvested in health" (Pg. 1174). Several newspapers also lauded the scheme as one of the world's largest public healthcare schemes (BBC News, 2018). Respondents also seem to be excited about the scheme, desire to scale it up to the next level, and expect a positive impact on the health system. As the scheme's focus is rural, it is also likely to increase the supply of healthcare facilities and improve the quality of health services in rural areas. The scheme impanels both public and private hospitals, and, therefore, the competition between them would probably also lead to reforms in the public sector. Additionally, it would also facilitate employment in rural areas. 


\begin{tabular}{|c|c|}
\hline Negative topics & Positive topics \\
\hline $\begin{array}{l}\text { Prevent fraud and fake cases such as abortions } \\
\text { Low pain in the process of the scheme } \\
\text { Focus on critical diseases such as cancer } \\
\text { The danger of oppression should be avoided } \\
\text { neglect death } \\
\text { Plight symptom of drug corruption } \\
\text { Limited payment of the extra fee for the } \\
\text { mortal bearer } \\
\text { Concern regarding the usage of taxpayers' } \\
\text { money only for nontaxpayers } \\
\text { Fees are harmful }\end{array}$ & $\begin{array}{l}\text { Young angel child } \sim \text { the birth of a baby girl as the first } \\
\text { beneficiary under this scheme } \\
\text { New strengthen vision } \sim \text { rapid acceptance with a high reach } \\
\text { A flawless and bold effort to reform care } \\
\text { Join the government to make it smart, superb, and better } \\
\text { and boost proudness } \\
\text { Support patient-partner model adopt real partnership } \\
\text { concept } \\
\text { Dream, enthusiast, robust landmark for citizens } \\
\text { Core global interest for talks } \\
\text { The scheme addresses developing/detecting cures by } \\
\text { professional doctors } \\
\text { Blessed with modern facilities and experts } \\
\text { Excellent model }\end{array}$ \\
\hline
\end{tabular}

Table 1. Positive and Negative Topics of '\#AyushmanBharat' Tweets

However, after two years of implementation, the high expectations from the scheme seem to be fading away. The budgetary allocation for the 'Ayushman Bharat' scheme over the years has been argued to be grossly inadequate (Chatterjee, 2019a; Ghosh and Quadeer, 2019; Chatterjee, 2019b). In 2018-19, the budget allocation for PMJAY was 20000 million INR and was increased to 64000 million, which was much less than what was required (420.73 billion) to fund the minimum scale and depth of the coverage that the scheme promises (Ghosh \& Quadeer, 2019). Two years after the launch of the scheme, many analysts have termed the budget allocation to be a token gesture (Chatterjee, 2019a; Ghosh \& Quadeer, 2019).

\begin{tabular}{|rl|}
\hline \multicolumn{1}{|c|}{ Concerns } \\
\hline $\mathbf{1 .}$ & Issues observed in previous programs other than PMJAY \\
\hline $\mathbf{2}$. & Lack of focus on quality \\
\hline $\mathbf{3 .}$ & Providers supply induced demand and fraud \\
\hline $\mathbf{4 .}$ & Limited reduction in the healthcare expenditures of beneficiaries \\
\hline $\mathbf{5 .}$ & Concerns about PMJAY as per the tweets related to PMJAY \\
\hline $\mathbf{6 .}$ & Process issues \\
\hline $\mathbf{7 .}$ & Fraud and drug corruption \\
\hline $\mathbf{8 .}$ & Extra fees from beneficiaries \\
\hline $\mathbf{9 .}$ & Status after 2 years of program implementation \\
\hline $\mathbf{1 0}$ & Not adequately addressed \\
\hline $\mathbf{1 1 .}$ & Limited evidence to either support or reject \\
\hline $\mathbf{1 2}$ & Not adequately addressed \\
\hline
\end{tabular}

Table 2. Citizens' Concerns and The Status of the Program's Implementation (from the experts) 
Although many people have benefited from similar schemes, there are consistent concerns that remain unaddressed. For example, although access to hospital care and utilization among lowincome families has increased, the current scheme, like past schemes, has had a limited impact on the health expenditures of the target population (Prinja et al., 2017; Maurya \& Ramesh, 2019). Earlier analysts argued extensively about the leakages and wastes generally observed in the health insurance model of providing hospitalization care, which can lead to a significant increase in healthcare costs. These concerns were both raised by experts (Brundtland, 2018; Ghosh \& Quadeer, 2019) and government-commissioned reports (Planning Commission, 2011). Two years after the launch of the scheme, fraud by hospitals continues to plague the scheme; however, the government remains optimistic about their ability to control the adverse effects of the model (NITI Aayog GOI, 2019).

Respondents also expressed disappointment as the scheme did not cover primary care or outpatient-based care (OPD care). The importance of covering OPD care has been emphasized by various experts' reports (Planning Commission, 2011; La Forgia \& Nagpal, 2012), and there have been some experiments by previous schemes such as RSBY (RSBY Newsletter, 2014). During in-depth interviews, the vice president of one of the leading insurance companies in India commented that "in OPD care the ticket price is very small whereas operational costs are high. Insuring OPD care means a vast number of claims, and therefore checking for fraud will be very difficult". Although there has been some discussion so far, primary care or OPD care remains uncovered in the 'Ayushman Bharat' scheme.

Negative Topics The negative topics raised in the tweets are related to the design of the program (Table 1). Our discussion with the experts revealed that hospitals have the autonomy to select treatment packages, and, therefore, they have an incentive to choose packages that are higher paying. Given the lack of standard treatment guidelines and a large volume of cases, hospitals engage in fraudulent behavior by making fake claims or claiming much higher amounts, as observed in the previous schemes. Similar concerns have also been raised by various experts and commentators (Prinja et al., 2017; Maurya \& Ramesh, 2019). In-depth interviews with the experts suggested that this is one of the main concerns in the design of the scheme. The former Director-General of WHO, Brutland (2018), noted in an article in 'The Lancet' that "India's poorly regulated private hospitals will be only too pleased to meet this demand, but as previous hospital insurance schemes have shown in India, this could result in people being given expensive diagnostic and surgical procedures they don't need." (Pg. 1175) The national office of the World Health Organization, India office, also noted his apprehension about the "limited capacity amongst Indian states in identification and enrolment of beneficiaries, designing the benefit package, fixing the package rate, empanelment of facilities, monitoring and regulation and fraud detection" (Laharia, 2018, pg. 495).

The implementing agency, the National Health Authority of India (NHAI), seems to be conscious of this concern and has made efforts to address this concern, including seeking technical expertise from various agencies (Economic Times, 2018). However, it is too early to comment on the effectiveness of the measures taken to control fraud. By May 8, 2020, 164 hospitals had been de-empaneled across the country due to engaging in fraudulent behavior. However, our interviews with hospital managers suggested that more prominent hospitals were empaneled in the program because of pressure from the government. Nevertheless, they do not accept these patients as the rates offered in the PMJAY scheme are much lower. 
On the other hand, smaller hospitals use this as an opportunity to make profits by engaging in fraudulent behavior. Fraudulent behavior not only occurs during hospitalization, but it also may emerge during the enrollment of beneficiaries in terms of issuing fake cards that can be later used to make claims in collusion with hospitals without providing any services. Responding to a question in the upper house of Parliament, the State Minister of Ministry of Health and Family reported that out of 120 million cards issued so far, 71027 cards were found to be fraudulent with the claimed amount of around Rs. 4.5 million (Government of India, 2020). To what extent these efforts have been successful is difficult to ascertain because no data exist on the extent of fraudulent cards in other health insurance programs.

The findings also suggest that a few issues in the scheme design have also existed in previous schemes and continue in the present design. As per the scheme design, there is no copayment in the scheme. Beneficiaries can receive treatment at the empaneled hospital without paying as all components of care-bed charges, medicines, investigation, and food are included in the package. Due to limited awareness among beneficiaries about the package details, this gets exploited by hospitals as they collect additional monies for various services, as observed in other schemes (Maurya \& Ramesh, 2019). Another way that hospitals collect monies from beneficiaries is when beneficiaries are unsure of the reimbursement from insurance companies. Insurance companies tend to reject claims on trivial technical issues to maintain profits, as found in other schemes (Maurya \& Srivastava, 2019). Anticipating this rejection, hospitals tend to collect money from beneficiaries before providing treatment, although the program design expects the treatment to be free at the time that the service is consumed. Third, in other schemes, extensive delays in insurance companies reimbursing providers have been observed (Maurya, 2018). Delays, coupled with the probability of rejection make hospitals unsure whether they will get paid for their claims, and, therefore, they collect money from the beneficiaries. Public health expert Sulakshana Nandi, the National Joint Convener of the Jan Swasthya Abhiyan, one of the most vocal NGOs in the health sector, commented that "due to power asymmetry and the absence of adequate regulation and grievance redressal systems private hospitals end up taking co-payments or making patients buy medicines, both of which are illegal under these schemes" (Chatterjee, 2019a, pg. 491).

Such concerns have been raised by the people at the time of the launch of the scheme, but the evidence regarding the efforts that have been made to control this is not clear. Reports from the 'Ayushman Bharat' suggest that most grievances are still about the collection of additional monies (National Health Authority, 2019). The beneficiaries have a limited voice as they can only lodge a complaint in the online grievance system or by calling the helpline. The widespread illiteracy in rural areas suggests that this is not an easy task for most of the beneficiaries. Though the beneficiary can choose the hospital, once the beneficiary has consented to be treated by a hospital and his/her card has been swiped, he/she cannot change hospitals.

There is also a discussion of the concerns related to coverage of the scheme. 'Ayushman Bharat' has substantially increased the depth of coverage compared to previous schemes. For example, RSBY only covered expenditures up to 395 USD per family per year, which was grossly insufficient for many types of care, such as cancer treatment and cardiac surgeries, both common in India, even among low-income families. 'Ayushman Bharat' covers expenditures up to 6590 USD, which is enough for treatment in these cases. However, as all these expenditures are financed through general tax revenues and targeted to low-income 
families, this will increase the tax burden on high-income families given the very low tax base in India, as only 3.8\% of the population paid income taxes in 2018-19 (Economic Times, 2020). This challenge needs to be recognized among policymakers as the general tax financing of health insurance in a country context with lower levels of formal employment such as India may sound like a pragmatic approach; however, it may lead to issues related to the solidarity among society.

Final Thoughts Public participation in policy design may result in diverse perspectives and conflicting goals and require trade-offs (Komor \& Bazilian, 2005) if there is wider participation. However, it may bias the data if there are certain population segments and political activism (Medglia \& Zheng, 2017). This challenge may be further heightened if the data are collected through SM due to ingroup-outgroup bias (Tajfel \& Turner, 2004; Hogg \& Reid, 2006), where people with similar beliefs may organize themselves in groups amplifying and re-enforcing each other's beliefs while belittling other groups that have different beliefs.

The findings include the analysis of tweets from various groups of the population: common citizens, government officials and agencies, magazines, newspapers, academic journals, and healthcare stakeholders. Government officials and agencies are expected to express positive sentiments and therefore represent one group with a positive belief system. However, magazines, newspapers, academic journals, and healthcare stakeholders tend to highlight the gaps that existed in previous schemes and therefore represent other groups with another belief system. We found that negative tweets were retweeted more often than positive tweets, creating a reinforcement and amplification of the belief system and thus presenting the possibility of intergroup bias, the dark side of SM analysis.

SM platforms are also considered to be effective and convenient tools for fake news, misinformation, and misleading directions. Considering these anomalies, it becomes very critical to incorporate citizens' opinions generated on various SM platforms. Wrong information can be taken as the most important piece of news because of the manipulation occurring on SM platforms. One of the observations from the dataset highlights that people share (e.g., retweet) more tweets that contain more negative sentiments. With this trend, citizen engagement can be derived in the direction of destroying the actual benefits of the scheme.

In all of the abovementioned online engagement disasters, various agencies monitor citizens' activities on SM, disgruntled citizens damage the public reputation when they rant about their experiences, other users bully each other, and misinformation and aggressive social engagement cause social tension. However, despite the many knowledge extraction benefits $\mathrm{SM}$ platforms offer, they are not immune to these relational ills either.

\subsection{Theoretical Implications}

Table 3 compares the public's views and experts' views on the key concerns related to the scheme. The results of our analysis interestingly show that the issues raised by the public are very close to those of experts. This finding contradicts some of the literature strands on policymaking processes. For example, Weisberg (2001) argued that policymakers should ignore public opinion as it reflects only wishes and preferences and no costs or risks associated with policy criteria; therefore, public opinion cannot coincide with the required policy choices. It is also argued that efforts to engage a sizeable public base in policy decisions are not fruitful as diverse perspectives may result in conflicting goals and require trade-offs (Komor \& Bazilian, 
2005). Further representativeness of all population segments and political activism can bias the data (Medglia \& Zheng, 2017).

\begin{tabular}{|l|l|}
\hline \multicolumn{1}{|c|}{ Public View } & \multicolumn{1}{c|}{ Expert View } \\
\hline Strengthen vision & Welcomed reform in underinvested healthcare \\
A flawless and bold effort & Lauded as the largest public healthcare scheme \\
Modern facilities and experts & No OPD care to void large claims and fraud \\
Prevent fraud and fake cases & Check hospital picking high-cost treatment package \\
Transparency - correct information & Hospitals' fraudulent behavior \\
Financial protection & \\
\hline
\end{tabular}

Table 3. Comparison of the public's and experts' views on the 'Ayushman Bharat' scheme

However, our analysis suggests that public opinion to a large extent matched the experts' opinions. We also performed user analysis to assess the representativeness of our sample. Apart from common citizens, our sample included several professional categories. The number of tweets from common citizens suggests that our sample represents public opinion. Although we can expect that government officials and agencies are expected to express positive sentiments, magazines, newspapers, and academic journals probably have more critical reviews of the scheme.

Furthermore, to understand the reasons for the match between experts' opinion and the public's opinion, we returned to the policy experts and executives who had significant experience and exposure to policymaking in India. It is found that health policy in India has not historically been a core political discourse compared to several other social issues such as caste and reservation, religion and state, foreign direct investment and economic self-reliance, etc. (Brass, 1994; Bayly, 2001; Dasgupta \& Qadeer, 2005; Sachan, 2014). For instance, a close examination of the election manifesto of the political parties in India shows little mention of their health policy orientations, resulting in very little political debate on the issue compared to other issues (Bhuyan, 2019; Chatterjee, 2019b). Only recently have differences in political viewpoints regarding policies related to health in India emerged, as observed in the case of 'Ayushman Bharat' between two dominant political parties (Chatterjee, 2019b). Usually, most political parties have similar viewpoints about healthcare in India (Kumar et al., 2017) and possibly do not see healthcare as a reason to differentiate themselves from other political parties; therefore, healthcare never becomes an essential component of election campaigns (Ahemed et al., 2016). Therefore, as health policy has never been a popular election topic in India, only informed citizens take an interest in health policy and comment on different platforms.

\subsection{Managerial Implications}

The analysis suggests that managers in public agencies should use SM to primarily inform and promote policies and programs. Public managers can significantly improve the design of programs and service delivery by routinely analyzing the feedback on SM. As also confirmed by the practitioners, health policy, due to being a politically non-controversial issue, does not very often attract extreme views. From a political perspective, the noncontroversial nature of healthcare in India results in a more rational debate rather than an emotional discussion. The 
continuity of the same policies during different political regimes also suggests that political ideology plays a limited role in health policy formulation in India. However, policymakers need to innovatively use online platforms including SM considering the social context. For example, the reports and public opinion suggest that most of the grievances on 'Ayushman Bharat' still regard the collection of additional monies. The beneficiaries have limited voices as they can only lodge complaints in the online grievance system or by calling the helpline. However, due to the widespread illiteracy in rural areas, this is not an easy task for most citizens. Policy designers may have to be more innovative to ease the use of online platforms despite a lack of a quick fix for social issues such as illiteracy. Additionally, even though SM helped obtain feedback from citizens on broader issues, granularity in those analyses is still missing. For example, OPD care constitutes a significant portion of out-of-pocket expenditures in India and therefore contributes significantly to the effect of improving healthcare expenditures (Garg \& Karan, 2009). However, the complexity of ensuring OPD care under insurance has been a significant challenge. Obviously, the social backwardness of the beneficiaries and high information asymmetry makes it difficult for the beneficiaries to engage in a granular discussion. Therefore, policymakers and SM platform designers need to be innovative to respond to the dual responsibility of educating citizens and helping them engage in critical discussions.

\subsection{Limitations and Future directions}

There are certain limitations of this study, and, therefore, the inferences from this study should be used with caution for the following reasons. Firstly, the data might not be the most accurate representative due to limitations of the effectiveness of how public data is extracted from Twitter. Future research could consider the development of an advanced text analytics technique to analyze all language tweets from a single dataset. Secondly, we attribute changes in the program design over the years to SMA; however, the program designers may have been influenced by the knowledge gained from other sources. Future research on policy co-design requires collecting SM data over longer periods and on the extent to which policy design agencies such as NHAI use these SM data. Given the potential of SMA, policy design, and codesign processes can be effective even in developing country context, where the most common approach for governments to consider policy feedback remains limited to elections.

\section{Conclusion}

In the Indian context, SM is increasingly used by citizens to express their opinion and public agencies to communicate information (Gul et al., 2017; Paruthi et al., 2020). However, its use has been primarily limited to one-way communication in a strategic political way. Our analysis suggests that although public agencies use SM to address grievances, their use of SM to engage stakeholders online to improve the design of public policy was limited. Tracing the evolution of program design indicated that there had been some changes in the program design over the last two years which addressed the concerns raised by citizens at the time of launch of the program. However, most of the critical issues remain unaddressed until today. Given the activism on SM by NHA, the agency responsible for improving the design of 'Ayushman Bharat', it can be inferred that SMA could play an essential role in enhancing policy design. Nevertheless, at present, SM continues to be primarily used for addressing grievances related to service delivery, as also done by various other government agencies. This could be considered as a rational approach to information use as per the 'Habermas Theory of Communication Action'. Using SMA for policy design requires a communicative approach 
that uses the information to create discussion groups on critical issues and consider different viewpoints of the stakeholders.

Our findings also suggest that contrary to expectations, citizens' opinions and experts' views were very similar despite the complex and technical nature of the scheme. This could be due to better awareness of the scheme among citizens due to their experience with similar schemes in the past and extensive propagation of information on the scheme in media, including SM.

\section{References}

Agarwal, S., \& Sureka, A. (2017, December). Investigating the role of Twitter in E-governance by extracting information on citizen complaints and grievances reports. In International Conference on Big Data Analytics (pp. 300-310). Springer, Cham.

Aggarwal, C. C., \& Subbian, K. (2012, April). Event Detection in Social Streams. In SDM (Vol. 12 , pp. 624-635).

Ahmed, S., Cho, J., \& Jaidka, K. (2017). Leveling the playing field: The use of Twitter by politicians during the 2014 Indian general election campaign. Telematics and Informatics, 34(7), 1377-1386.

Ahmed, W., \& Lugovic, S. (2019). Social media analytics: analysis and visualisation of news diffusion using NodeXL. Online Information Review. 43 (1), 149-160.

Akrout, H., \& Diallo, M. F. (2017). Fundamental transformations of trust and its drivers: A multi-stage approach of business-to-business relationships. Industrial Marketing Management, 66, 159-171.

Aleti, T., Harrigan, P., Cheong, M., \& Turner, W. (2016). An investigation of how the Australian brewing industry influence consumers on Twitter. Australasian Journal of Information Systems, 20. https://doi.org/10.3127/ajis.v20i0.1350

Alizadeh, T., Sarkar, S., \& Burgoyne, S. (2019). Capturing citizen voice online: Enabling smart participatory local government. Cities, 95, 102400. https://doi.org/10.1016/j.cities. 2019.102400

Androutsopoulou, A., \& Charalabidis, Y. (2018, April). A framework for evidence based policy making combining big data, dynamic modelling and machine intelligence. In Proceedings of the 11th International Conference on Theory and Practice of Electronic Governance (pp. 575$583)$.

Aquilino, W. S., \& Wright, D. L. (1996). Substance use estimates from RDD and area probability samples: Impact of differential screening methods and unit nonresponse. Public Opinion Quarterly, 60(4), 563-573.

Arnold, R. D. (1990). The logic of congressional action. Yale University Press.

Asher, M., Vora, Y., \& Maurya, D. (2015). An analysis of selected pension and health care initiatives for informal sector workers in India. Social Policy \& Administration, 49(6), 738-751.

Aswani, R., Kar, A. K., \& Ilavarasan, P. V. (2018a). Detection of spammers in twitter marketing: a hybrid approach using social media analytics and bio inspired computing. Information Systems Frontiers, 20(3), 515-530. 
Aswani, R., Kar, A. K., Ilavarasan, P. V., \& Dwivedi, Y. K. (2018b). Search engine marketing is not all gold: Insights from Twitter and SEOClerks. International Journal of Information Management, 38(1), 107-116.

Bali, A. S., \& Ramesh, M. (2015). Mark time: India's march to universal health care coverage. Social Policy \& Administration, 49(6), 718-737.

Barbosa, L., \& Feng, J. (2010, August). Robust sentiment detection on twitter from biased and noisy data. In Coling 2010: Posters (pp. 36-44).

Bayly, S. (2001). Caste, society and politics in India from the eighteenth century to the modern age (Vol. 3). Cambridge University Press.

BBC News, (2018). India unveils 'world's largest' public healthcare scheme. Available on 22 June 2019, Retrieved from http://www.bbc.com/news/world-asia-india-42899402.

Becker, G. S. (1983). A theory of competition among pressure groups for political influence. The quarterly journal of economics, 98(3), 371-400.

Beer, D., \& Burrows, R. (2007). Sociology and, of and in Web 2.0: Some initial considerations. Sociological research online, 12(5), 67-79.

Bekkers, V., Edwards, A., \& de Kool, D. (2013). Social media monitoring: Responsive governance in the shadow of surveillance?. Government Information Quarterly, 30(4), 335342.

Berry, J. M., \& Wilcox, C. (2018). The interest group society. Routledge.

Bertot, J. C., Jaeger, P. T., \& Grimes, J. M. (2010). Using ICTs to create a culture of transparency: E-government and social media as openness and anti-corruption tools for societies. Government information quarterly, 27(3), 264-271.

Bhuyan, A. (2019). In India, a tight election-with healthcare trailing the field. BMJ: British Medical Journal (Online), 365. https://doi.org/10.1136/bmj.12175

Blomkamp, E. (2018). The promise of co-design for public policy. Australian Journal of Public Administration, 77(4), 729-743.

Boubakri, N., Cosset, J. C., \& Saffar, W. (2008). Political connections of newly privatized firms. Journal of corporate finance, 14(5), 654-673.

Brabham, D. C. (2012). The myth of amateur crowds: A critical discourse analysis of crowdsourcing coverage. Information, Communication \& Society, 15(3), 394-410.

Brass, P. R. (1994). The politics of India since independence (Vol. 1). Cambridge University Press.

Brundtland, G. H. (2018). India's health reforms: the need for balance. http://dx.doi.org/10.1016/ S0140-6736(18)32387-0

Burger, A., \& Silima, T. (2006). Sampling and sampling design. Journal of Public Administration, 41(3), 656-668.

Cao, Q., Thompson, M. A., \& Yu, Y. (2013). RETRACTED: Sentiment analysis in decision sciences research: An illustration to IT governance. Decision Support Systems, 54(2), 10101015. 
Cataldi, M., Di Caro, L., \& Schifanella, C. (2010, July). Emerging topic detection on twitter based on temporal and social terms evaluation. In Proceedings of the tenth international workshop on multimedia data mining (pp. 1-10).

Chae, B. K. (2015). Insights from hashtag\# supplychain and Twitter Analytics: Considering Twitter and Twitter data for supply chain practice and research. International Journal of Production Economics, 165, 247-259.

Chatterjee, P. (2019a). Modi's health reforms: between hope and hype. The Lancet, 394(10208), 1495-1498.

Chatterjee, P. (2019b). Health debate rising around the upcoming Indian election. Available on Dec 2019, Retrieved from

https://dl.uswr.ac.ir/bitstream/Hannan/80065/1/2019\%20Lancet\%20Volume\%20393\%20 Issue $\% 2010180 \% 20 \mathrm{April} \% 20 \% 2831 \% 29$.pdf

Chau, M., \& Xu, J. (2012). Business intelligence in blogs: Understanding consumer interactions and communities. MIS quarterly, 36(4), 1189-1216.

Chun, S. A., \& Luna-Reyes, L. F. (2012). Social media in government. Government information quarterly, 29(4), 441-445.

Corcoran, N., \& Duane, A. (2018). Using Social Media to Enable Staff Knowledge Sharing in Higher Education Institutions. Australasian Journal of Information Systems, 22. https://doi.org/10.3127/ajis.v22i0.1647

Criado, J. I., Sandoval-Almazan, R., \& Gil-Garcia, J. R. (2013). Government Innovation through Social Media. Government Information Quarterly, 30(4), 319-326.

Curiskis, S. A., Drake, B., Osborn, T. R., \& Kennedy, P. J. (2020). An evaluation of document clustering and topic modelling in two online social networks: Twitter and Reddit. Information Processing \& Management, 57(2), 102034.

Cyr, D., Head, M., Larios, H., \& Pan, B. (2009). Exploring human images in website design: a multi-method approach. MIS quarterly, 539-566.

Dasgupta, R., \& Qadeer, I. (2005). The national rural health mission (NRHM): A critical overview. Indian J Public Health, 49(3), 138-40.

Downs, A. (1957). An economic theory of democracy. New York: Harper.

Economic Times, (2018, May). “NITI Aayog seeks World Bank's help to prevent fraud in health insurance scheme". Available on 12 Oct 2019, Retrieved from https://economictimes.indiatimes.com/news/politics-and-nation/niti-aayog-seeksworld-banks-help-to-prevent-fraud-in-health-insurance-scheme/articleshow/ 64051120.cms? from $=\mathrm{mdr}$

Eom, S. J., Hwang, H., \& Kim, J. H. (2018). Can social media increase government responsiveness? A case study of Seoul, Korea. Government information quarterly, 35(1), 109-122.

Eze, E., Gleasure, R., \& Heavin, C. (2016). How can mHealth applications that are developed in one area of the developing world be adapted for use in others?. Journal of Decision systems, 25(sup1), 536-541. 
Falco, E., \& Kleinhans, R. (2019). Digital participatory platforms for co-production in urban development: A systematic review. In Crowdsourcing: Concepts, Methodologies, Tools, and Applications (pp. 663-690). IGI Global.

Feldman, R. (2013). Techniques and applications for sentiment analysis. Communications of the ACM, 56(4), 82-89.

Fensel, D., Leiter, B., \& Stavrakantonakis, I. (2012). Social media monitoring. Semantic Technology Institute, Innsbruck, 16. Available on 15 June 2018, Retrieved from https://oc.sti2.at/sites/default/files/SMM\%20Handouts.pdf

Fredrickson, B. L., \& Losada, M. F. (2005). Positive Affect and the Complex Dynamics of Human Flourishing. American Psychologist, 60(7), 678-686. https://doi.org/10.1037/0003066X.60.7.678

Garg, C. C., \& Karan, A. K. (2009). Reducing out-of-pocket expenditures to reduce poverty: a disaggregated analysis at rural-urban and state level in India. Health policy and planning, 24(2), 116-128.

Ghosh, S. M., \& Qadeer, I. (2019). Pradhan Mantri Jan Arogya Yojana: A Paper Tiger. Social Change, 49(1), 136-143.

Gintova, M. (2019). Understanding government social media users: An analysis of interactions on immigration, refugees and citizenship canada twitter and facebook. Government Information Quarterly, 36(4), 101388. https://doi.org/10.1016/j.giq.2019.06.005

Government of India (2020). “Rajya Sabha Unstarred Question No-283" http://164.100.47.5/qsearch/QResult.aspx

Goyal, M., Gupta, N., Jain, A., \& Kumari, D. (2020). Smart Government E-Services for Indian Railways Using Twitter. In Micro-Electronics and Telecommunication Engineering (pp. 721731). Springer, Singapore.

Grindle, M. S., \& Thomas, J. W. (1991). Public choices and policy change: the political economy of reform in developing countries. Johns Hopkins Univ Pr.

Grover, P., Kar, A. K., \& Davies, G. (2018). “Technology enabled Health”-Insights from twitter analytics with a socio-technical perspective. International Journal of Information Management, 43, 85-97.

Grover, P., Kar, A. K., \& Ilavarasan, P. V. (2019a). Impact of corporate social responsibility on reputation-Insights from tweets on sustainable development goals by CEOs. International Journal of information management, 48, 39-52.

Grover, P., Kar, A. K., Dwivedi, Y. K., \& Janssen, M. (2019b). Polarization and acculturation in US Election 2016 outcomes-Can twitter analytics predict changes in voting preferences. Technological Forecasting and Social Change, 145, 438-460.

Gul, S., Mahajan, I., Nisa, N.T., Shah, T.A., Asifa, J., \& Ahmad, S. (2016). "Tweets speak louder than leaders and masses: An analysis of tweets about the Jammu and Kashmir elections 2014", Online Information Review, 40(7), 900-912. https://doi.org/10.1108/OIR-10-20150330 
Gupta, I., Chowdhury, S., Trivedi, M., \& Prinja, S. (2017). Do health coverage schemes ensure financial protection from hospitalization expenses? Evidence from eight districts in India. Journal of Social and Economic Development, 19(1), 83-93.

Habrmas, J. (1984). The Theory of Communicative Action: Reason and the Rationalization of Society (Vol. 1). Beacon Press.

Habermas, J. (2015). The Theory of Communicative Action: Lifeworld and Systems, a Critique of Functionalist Reason, Volume 2 (Vol. 2). John Wiley \& Sons.

Hacker, J., Wickramasinghe, N., \& Durst, C. (2017). Can health 2.0 address critical healthcare challenges? Insights from the case of how online social networks can assist in combatting the obesity epidemic. Australasian journal of information systems, 21, 1-17.

Hambrick, D. C., \& Abrahamson, E. (1995). Assessing managerial discretion across industries: A multimethod approach. Academy of Management Journal, 38(5), 1427-1441.

Hansen, D., Shneiderman, B., \& Smith, M. A. (2010). Analyzing social media networks with NodeXL: Insights from a connected world. Morgan Kaufmann.

He, W., \& Customer Co-creation, The Computer Journal, 57(12), 1909-1920.

Hedestig, U., Skog, D., \& Söderström, M. (2018, May). Co-producing public value through IoT and social media. In Proceedings of the 19th Annual International Conference on Digital Government Research: Governance in the Data Age (pp. 1-10).

Henry, D., Dymnicki, A. B., Mohatt, N., Allen, J., \& Kelly, J. G. (2015). Clustering methods with qualitative data: a mixed-methods approach for prevention research with small samples. Prevention science, 16(7), 1007-1016.

Hogg, M. A., \& Reid, S. A. (2006). Social identity, self-categorization, and the communication of group norms. Communication Theory, 16(1), 7-30.

Holvoet, N., \& Inberg, L. (2014). Taking stock of monitoring and evaluation systems in the health sector: Findings from Rwanda and Uganda. Health Policy and Planning, 29(4), 506516.

Howlett, M. (2019). Procedural policy tools and the temporal dimensions of policy design. Resilience, robustness and the sequencing of policy mixes. International Review of Public Policy, 1(1: 1), 27-45.

Howlett, M., Mukherjee, I., \& Woo, J. J. (2015). From tools to toolkits in policy design studies: the new design orientation towards policy formulation research. Policy $\mathcal{E}$ Politics, 43(2), 291-311.

Huh, J., Yetisgen-Yildiz, M., \& Pratt, W. (2013). Text classification for assisting moderators in online health communities. Journal of Biomedical Informatics, 46(6), 998-1005.

IRDA. Annual Report, (2016). Insurance Regulatory and Development Authority of India (2016), New Delhi. Available on 5 Sep 2018, Retrieved from http://dhc.co.in/uploadedfile/1/2/1/IRDAI\%20\%20(Health\%20Insurance)\%20Regulations\%202016.pdf

Jones, B. D. (1994). Reconceiving decision-making in democratic politics: Attention, choice, and public policy. University of Chicago Press.

Khawaja, S. (2011). Good governance and result based monitoring. Poorab Academy, Islamabad. 
King, S. C., Meiselman, H. L., \& Carr, B. T. (2013). Measuring emotions associated with foods: Important elements of questionnaire and test design. Food Quality and Preference, 28(1), 8-16.

Komor, P., \& Bazilian, M. (2005). Renewable energy policy goals, programs, and technologies. Energy Policy, 33(14), 1873-1881.

Ku, L. W., Liang, Y. T., \& Chen, H. H. (2006, March). Opinion extraction, summarization and tracking in news and blog corpora. In AAAI spring symposium: Computational approaches to analyzing weblogs (Vol. 100107, pp. 1-167).

Kumar, A., \& Sharma, A. (2017). Systematic Literature Review on Opinion Mining of Big Data for Government Intelligence. Webology, 14(2). Available on 14 April 2018, Retrieved from https://www.webology.org/2017/v14n2/a156.pdf

Kumar, D., Kumar, R., Chauhan, R., Chander, V., \& Raina, S. K. (2017). Pattern of health promises for Indian democracy: A qualitative review of political manifestos. Journal of family medicine and primary care, 6(3), 455-459.

La Forgia, G., \& Nagpal, S. (2012). Government-sponsored health insurance in India: Are you covered?. The World Bank. Available on 27 July 2018, Retrieved from http://crossasiarepository.ub.uni-heidelberg.de/3506/1/Goverment $\% 20$ sponsored $\% 20$ Health\%20Insur ance\%20India.pdf

Lahariya, C. (2018). 'Ayushman Bharat'program and universal health coverage in India. Indian pediatrics, 55(6), 495-506.

Lau, R. Y., Li, C., \& Liao, S. S. (2014). Social analytics: Learning fuzzy product ontologies for aspect-oriented sentiment analysis. Decision Support Systems, 65, 80-94.

Lim, W. M., Lim, A. L., \& Phang, C. S. C. (2019). Toward a conceptual framework for social media adoption by non-urban communities for non-profit activities: Insights from an integration of grand theories of technology acceptance. Australasian Journal of Information Systems, 23. https://doi.org/10.3127/ajis.v23i0.1835

Lin, H.-F. (2014). A multi-stage analysis of antecedents and consequences of knowledge management evolution. Journal of Knowledge Management, 18(1), 52-74.

Lindaman, K., \& Haider-Markel, D. P. (2002). Issue evolution, political parties, and the culture wars. Political Research Quarterly, 55(1), 91-110.

Linders, D. (2012). From e-government to we-government: Defining a typology for citizen coproduction in the age of social media. Government information quarterly, 29(4), 446-454.

Liu, X., Zhang, W. J., Tu, Y. L., \& Jiang, R. (2008). An analytical approach to customer requirement satisfaction in design specification development. Engineering Management, IEEE Transactions on, 55(1), 94-102.

Loukis, E., \& Charalabidis, Y. (2015). Active and passive crowdsourcing in government. In Policy practice and digital science (pp. 261-289). Springer, Cham.

Loukis, E., Charalabidis, Y., \& Androutsopoulou, A. (2017). Promoting open innovation in the public sector through social media monitoring. Government information quarterly, 34(1), 99-109. 
Malsbender, A., Hoffmann, S., \& Becker, J. (2014). Aligning Capabilities and Social Media Affordances for Open Innovation in Governments. Australasian Journal of Information Systems, 18(3). https://doi.org/10.3127/ajis.v18i3.1100

Mathauer, Inke, and Guy Carrin. 2011. 'The Role of Institutional Design and Organizational Practice for Health Financing Performance and Universal Coverage'. Health Policy 99 (3): 183-192.

Maurya, D. (2018). Contracting out: making it work. Policy Design and Practice, 1(4), 281-297.

Maurya, D., \& Ramesh, M. (2019). Program design, implementation and performance: the case of social health insurance in India. Health Economics, Policy and Law, 14(4), 487-508.

Maurya, D., \& Srivastava, A. K. (2019). Managing partner opportunism in public-private partnerships: the dynamics of governance adaptation. Public Management Review, 21(10), 1420-1442.

Medaglia, R., \& Zheng, L. (2017). Mapping government social media research and moving it forward: A framework and a research agenda. Government information quarterly, 34(3), 496-510.

Melville, P., Sindhwani, V., \& Lawrence, R. (2009). Social media analytics: Channeling the power of the blogosphere for marketing insight. Proc. of the WIN, 1(1), 1-5.

Meyer, A. D., \& Goes, J. B. (1988). Organizational assimilation of innovations: A multilevel contextual analysis. Academy of Management Journal, 31(4), 897-923.

Miah, S. J., Hasan, N., Hasan, R., \& Gammack, J. (2017). Healthcare support for underserved communities using a mobile social media platform. Information Systems, 66, 1-12.

Mitchell, A., Mahal, A., \& Bossert, T. (2011). Healthcare utilisation in rural Andhra Pradesh. Economic and Political Weekly, 15-19. https://www.jstor.com/stable/27918082

Morgan, K., Cheong, M., \& Bedingfield, S. (2018). "Power to the People!": Social Media Discourse on Regional Energy Issues in Australia. Australasian Journal of Information Systems, 22. https://doi.org/10.3127/ajis.v22i0.1678

National Health Authority of India (2019). Annual Report 2018-19. Available on 16 Dec 2019, Retrieved from https://main.mohfw.gov.in/basicpage/annual-report-2018-19

National Sample Survey Office (2015). "Key Indicators of Social Consumption in Health NSS 71st Round." National Sample Survey Organization. Available on 19 Jan 2018, Retrieved from http://www.mospi.gov.in/sites/default/files/publication_reports/ KI_Health 75th_ Final.pdf

Netshakhuma, N. S. (2019). Assessment of the status of the social media records: the case of the Mpumalanga government, South Africa. Journal of Archival Organization, 16(4), 178196.

NITI Aayog, Government of India (2019). 'Health System for a New India: Building Blocks, Potential Pathways to Reform'. Available on 12 Feb 2020, Retrieved from https://niti.gov.in/sites/default/files/2019-11/NitiAayogBook_compressed.pdf.

Nowell, L. S., Norris, J. M., White, D. E., \& Moules, N. J. (2017). Thematic analysis: Striving to meet the trustworthiness criteria. International Journal of Qualitative Methods, 16(1), 113. https://doi.org/10.1177/1609406917733847 
Pak, A., \& Paroubek, P. (2010, May). Twitter as a corpus for sentiment analysis and opinion mining. In LREc (Vol. 10, No. 2010, pp. 1320-1326).

Pang, B., \& Lee, L. (2009). Opinion mining and sentiment analysis. Comput. Linguist, 35(2), 311-312.

Paruthi, M., Mendiratta, P., \& Gupta, G. (2020). Young Citizen's Political Engagement in India: Social Media Use by Political Parties. In Examining the Roles of IT and Social Media in Democratic Development and Social Change (pp. 115-132). IGI Global.

Peters, B. G. (2015). State failure, governance failure and policy failure: Exploring the linkages. Public Policy and Administration, 30(3-4), 261-276.

Peters, B. G., Capano, G., Howlett, M., Mukherjee, I., Chou, M. H., \& Ravinet, P. (2018). Designing for policy effectiveness: Defining and understanding a concept. Cambridge University Press.

Picazo-Vela, S., Fernández-Haddad, M., \& Luna-Reyes, L. F. (2016). Opening the black box: Developing strategies to use social media in government. Government information quarterly, 33(4), 693-704.

Planning Commission (2011). 'High Level Expert Group Report on Universal Health Coverage for India'. Available on 21 March 2017, Retrieved from http://ideas.repec.org/p/ess/wpaper/id4646.html.

Poell, T., \& Rajagopalan, S. (2015). Connecting activists and journalists: Twitter communication in the aftermath of the 2012 Delhi rape. Journalism Studies, 16(5), 719-733.

Prinja, S., Chauhan, A. S., Karan, A., Kaur, G., \& Kumar, R. (2017). Impact of publicly financed health insurance schemes on healthcare utilization and financial risk protection in India: a systematic review. PloS one, 12(2). https://doi.org/10.1371/journal.pone.0170996

Qaiser, S., \& Ali, R. (2018). Text mining: use of TF-IDF to examine the relevance of words to documents. International Journal of Computer Applications, 181(1), 25-29.

Rathore, A. K., \& Ilavarasan, P. V. (2020). Pre-and post-launch emotions in new product development: Insights from twitter analytics of three products. International Journal of Information Management, 50, 111-127.

Rathore, A. K., Ilavarasan, P. V., \& Dwivedi, Y. K. (2016). Social media content and product co-creation: an emerging paradigm. Journal of Enterprise Information Management, 29(1), 7-18.

Rathore, A. K., Kar, A. K., \& Ilavarasan, P. V. (2017). Social media analytics: Literature review and directions for future research. Decision Analysis, 14(4), 229-249.

Ren, Y., Wang, R., \& Ji, D. (2016). A topic-enhanced word embedding for Twitter sentiment classification. Information Sciences, 369, 188-198.

RSBY Newsletter, (2013). Ministry of Labour and Employment Government of India and IndoGerman Social Security Programme, and MoLE, Govt. of India and German Development Cooperation. 2014. RSBY Connect Issue No. 24. New Delhi. Available on 15 May 2018, Retrieved from http://www.rsby.gov.in/Documents.aspx?ID=16.

Sachan, D. (2014). Health gets greater attention in the 2014 Indian elections. The Lancet, 383(9925), 1281-1282. 
Steen, M., Manschot, M., \& De Koning, N. (2011). Benefits of co-design in service design projects. International Journal of Design, 5(2), 53-60.

Surowiecki, J. (2004). The wisdom of crowds: Why the many are smarter than the few and how collective wisdom shapes business. Economies, Societies and Nations, 296, 5.

Sutton, J. N. (2009). Social media monitoring and the democratic national convention: New tasks and emergent processes. Journal of Homeland Security and Emergency Management, 6(1). https://doi.org/10.2202/1547-7355.1601

Taeihagh, A. (2017). Crowdsourcing: a new tool for policy-making?. Policy Sciences, 50(4), 629647.

Tajfel, H., \& Turner, J. C. (2004). The social identity theory of intergroup behavior. In J. T. Jost, \& J. Sidanius (Eds.), Political Psychology: Key readings (key readings in social Psychology) (pp. 276-293). New York, NY: Psychology Press.

Tuarob, S., Tucker, C. S., Salathe, M., \& Ram, N. (2014). An ensemble heterogeneous classification methodology for discovering health-related knowledge in social media messages. Journal of Biomedical Informatics, 49, 255-268.

Verma, R. K., Kumar, S., \& Ilavarasan, P. V. (2017). Government portals, social media platforms and citizen engagement in India: Some insights. Procedia computer science, 122, 842-849.

Wan, C., Shen, G. Q., \& Yu, A. (2015). Key determinants of willingness to support policy measures on recycling: A case study in Hong Kong. Environmental Science $\mathcal{E}$ Policy, 54, 409-418.

Wang, H., Lu, Y., \& Zhai, C. (2010, July). Latent aspect rating analysis on review text data: a rating regression approach. In Proceedings of the 16th ACM SIGKDD international conference on Knowledge discovery and data mining (pp. 783-792). ACM.

Warf, B. (2016). e-Government in Asia: Origins, politics, impacts, geographies. Chandos Publishing.

Weissberg, R. (2001). Why policymakers should ignore public opinion polls. Washington, DC: Cato Institute.

Williamson, O. E. (1993). Calculativeness, trust, and economic organization. The journal of law and economics, 36(1, Part 2), 453-486.

Yang, S., \& Zhang, H. (2018). Text mining of Twitter data using a latent Dirichlet allocation topic model and sentiment analysis. Int. J. Comput. Inf. Eng, 12, 525-529.

Yoon, S., Elhadad, N., \& Bakken, S. (2013). A practical approach for content mining of tweets. American journal of preventive medicine, 45(1), 122-129.

Zaller, J. R. (1992). The nature and origins of mass opinion. Cambridge university press.

Zhang, B., \& Vos, M. (2014). Social media monitoring: aims, methods, and challenges for international companies. Corporate Communications: An International Journal. 19(4), 371383. https://doi.org/10.1108/CCIJ-07-2013-0044

Copyright: (c) 2021 authors. This is an open-access article distributed under the terms of the Creative Commons Attribution-NonCommercial 3.0 Australia License, which permits non- 
commercial use, distribution, and reproduction in any medium, provided the original author and AJIS are credited.

doi: https://doi.org/10.3127/ajis.v25i0.2965

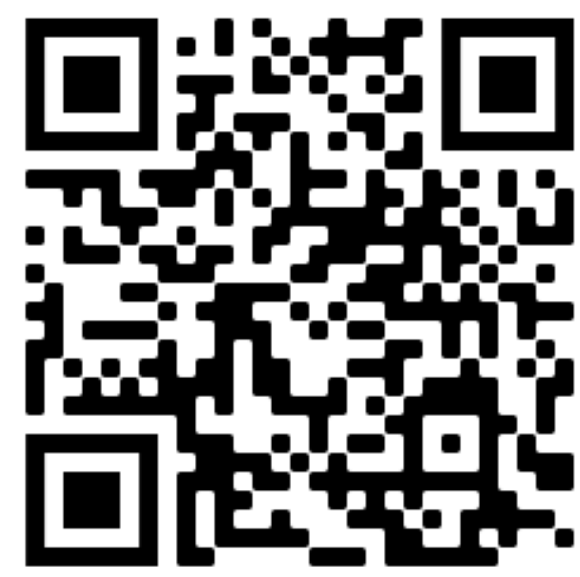

